\title{
Estratégia para Controlar o Staphylococcus Aureus Resistente à Meticilina: A Experiência de Cinco Anos de um Hospital
}

\author{
Strategy to Control Methicillin-Resistant Staphylococcus Aureus: \\ The 5 Year Experience of a Hospital
}

\author{
David PERES ${ }^{1}$, Isabel NEVES ${ }^{1,2,3}$, Fernanda VIEIRA ${ }^{1}$, Ilda DEVESA ${ }^{1}$ \\ Acta Med Port 2014 Jan-Feb;27(1):67-72
}

\section{RESUMO}

Introdução: O Staphylococcus aureus resistente à meticilina é um dos microrganismos multirresistentes mais frequentemente implicados em infeções associadas a cuidados de saúde. Definiu-se como objetivo implementar uma estratégia multimodal para controlar este microrganismo num hospital.

Material e Métodos: Procedimento baseado em rastreio ativo e medidas de isolamento numa população selecionada (doentes provenientes de outras instituições de saúde e lares ou com historial de internamento/ staphylococcus aureus resistente à meticilina; doentes dos cuidados intensivos e intermédios e, nos restantes serviços, rastreio aos contactos diretos se detetado um novo caso de staphylococcus aureus resistente à meticilina e, desde 2012, hemodialisados). Outras ações paralelas: (1) revisão das normas Precauções Básicas e Isolamento; (2) reforço dos pontos de desinfeção alcoólica das mãos; (3) sessões de esclarecimento aos profissionais de saúde; (4) folha 'Alerta de staphylococcus aureus resistente à meticilina' no processo dos doentes; (5) panfleto de informação aos doentes/ visitas; (6) monitorização do procedimento através de auditoria e (7) descolonização de doentes nos cuidados intensivos e intermédios, com rastreios de follow-up.

Resultados: Entre 2007 e 2012 registou-se um decréscimo da proporção de staphylococcus aureus resistente à meticilina de $66 \%$ para $57 \%$ e da densidade de incidência de 1,80 para 0,68 casos por mil dias de internamento $(p<0,001 ; \operatorname{RR} 0,38$; IC95\%: $0,29-0,49)$. Discussão/Conclusão: De acordo com dados europeus publicados, referentes a isolados no sangue e líquor, Portugal foi o país com maior proporção de staphylococcus aureus resistente à meticilina em 2011. Utilizando este critério de inclusão, o nosso hospital revelou uma proporção de staphylococcus aureus resistente à meticilina inferior à média nacional (34\% versus $55 \%$ ). A estratégia multimodal demonstrou ser eficaz na diminuição dos casos de staphylococcus aureus resistente à meticilina. Salvaguarda-se a necessidade de realizar vigilância epidemiológica deste agente, bem como monitorização da aplicação do procedimento, com feedback aos profissionais de saúde.

Palavras-chave: Staphylococcus aureus Resistente à Meticilina; Controlo da Infecção; Portugal.

\section{ABSTRACT}

Introduction: Methicillin-resistant Staphylococcus aureus remains one of the principal resistant pathogens causing serious healthcareassociated infections. The objective of this study was to control and monitor methicillin-resistant Staphylococcus aureus cases using multimodal strategy in a Portuguese hospital.

Material and Methods: Multistep procedure involving isolation measures and active surveillance cultures in a selected population (patients from other hospitals and nursing homes; history of hospitalization/ methicillin-resistant Staphylococcus aureus; intensive and intermediate care patients and, in other inpatient services, direct contacts of newly detected methicillin-resistant Staphylococcus aureus patients and, since 2012, patients doing hemodialysis). Other parallel activities: (a) review of isolation and standard precautions policy, (b) reinforcement of alcohol-based handrubs at point of patient care, (c) information sessions to health professionals, (d) targeted information flyer for health professionals, (e) information leaflet for patients/ visitors; (f) procedure monitoring by audit (g) patient decolonization in intensive and intermediate care units, with follow-up screenings.

Results: Between 2007 and 2012, methicillin-resistant Staphylococcus aureus surveillance detected a decrease in proportion from $66 \%$ to $57 \%$ and, in density of incidence, from 1.80 to 0.68 cases per thousand days of hospitalization $(p<0.001 ; \mathrm{RR} 0.38 ; \mathrm{Cl} 95 \%$ : 0.29-0.49).

Discussion/Conclusion: According to published European data, using blood and cerebrospinal fluid isolates only, Portugal was the country with the highest level of methicillin-resistant Staphylococcus aureus in 2011. Using this inclusion criteria, our hospital reveled a proportion of methicillin-resistant Staphylococcus aureus below its national level (34\% versus 55\%) in 2011 . Fighting methicillinresistant Staphylococcus aureus using a multimodal strategy is being effective in a high endemic level hospital, but perseverance is needed through continuous surveillance of cases, feed-back to professionals and procedure audits.

Keywords: Methicillin-Resistant Staphylococcus aureus; Infection Control; Staphylococcal Infections; Portugal.

\section{INTRODUÇÃo}

O Staphylococcus aureus é um microrganismo que integra a população microbiana da pele e narinas de indivíduos saudáveis. A maior parte das estirpes são sensíveis a vários antibióticos e as infeções são tratadas com eficácia. No entanto, existem estirpes que são resistentes à meticilina $e$ que se caracterizam por serem, também, resistentes a um amplo conjunto de outros antibióticos, o que torna o tratamento de infeções por Staphylococcus aureus resistente à meticilina (MRSA) difícil e dispendioso. ${ }^{1} \mathrm{~A}$ falta de alternativas terapêuticas deste agente patogénico é uma fonte

\footnotetext{
1. Comissão de Controlo de Infeção. Unidade Local de Saúde de Matosinhos. Matosinhos. Portugal.

2. Serviço de Infeciologia. Unidade Local de Saúde de Matosinhos. Matosinhos. Portugal.

3. Comissão de Antimicrobianos. Unidade Local de Saúde de Matosinhos. Matosinhos. Portugal.

Recebido: 01 de Agosto de 2013 - Aceite: 23 de Dezembro de 2013 | Copyright @ Ordem dos Médicos 2014
} 
de preocupação a nível nacional e internacional, tendo a Infectious Diseases Society of America incluído o MRSA na lista dos 'bad bugs, no drugs', conhecidos pela mnemónica ESKAPE. ${ }^{2}$ Tal como Grundmann et al referem, há evidência que as infeções nosocomiais por MRSA aumentam a morbilidade, risco de mortalidade e custos. ${ }^{3}$

O MRSA é, hoje, o microrganismo patogénico multirresistente mais frequentemente isolado nos hospitais em muitas partes do mundo ${ }^{4}$ assim como em Portugal, com uma taxa de resistência à meticilina de 47,5\% em 2003 descrita por Melo-Cristino et al. ${ }^{5}$ Dados mais recentes indicam Portugal como o país Europeu com a maior proporção de MRSA (referente somente a isolados no sangue e líquor), atingindo os 55\% em 2011. ${ }^{4}$ Historicamente, o MRSA era um microrganismo associado a infeções nosocomiais, no entanto, mais recentemente estirpes com fenótipos distintos emergiram na comunidade ${ }^{6}$ levando Klevens et al a propor que o MRSA fosse classificado como associado a cuidados de saúde (distinguindo os que são detetados no hospital versus detetados na comunidade) e adquirido na comunidade. ${ }^{7}$ Este último estudo estimou que, em 2005, ocorreram cerca de 18650 mortes e 94360 infeções invasivas por MRSA nos Estados Unidos da América, concluindo que 'constitui um grave problema de saúde pública, primariamente relacionado com os cuidados de saúde, mas que deixou de estar confinado aos hospitais ou outras instituições de saúde'. ${ }^{7}$ De facto, num estudo Português recente, recorrendo a métodos de biologia molecular, é documentada a vasta disseminação do MRSA entre hospitais e a comunidade. ${ }^{8}$

A nível hospitalar, a fonte de transmissão cruzada desta bactéria são os doentes infetados ou colonizados. ${ }^{9}$ Segundo Henderson 'a via de transmissão primária dentro de um hospital parece ser, de doente para doente, as mãos dos profissionais de saúde'. ${ }^{10} \mathrm{O}$ risco de colonização/infeção por MRSA aumenta com o tempo de internamento, gravidade da doença de base, número de cirurgias, manipulações e exposição prévia a antibióticos. ${ }^{9}$ Segundo Solberg, a prevalência de MRSA em determinada instituição de saúde depende (1) da introdução constante deste microrganismo por novas admissões, (2) dos reservatórios na instituição devido a colonização e disseminação entre doentes e profissionais e (3) da proporção de estirpes que se tornaram resistentes devido a pressão seletiva dos antibióticos. ${ }^{11}$

O presente estudo propôs-se aplicar uma estratégia multimodal para controlar este microrganismo num hospital com níveis endémicos de MRSA.

\section{MATERIAL E MÉTODOS}

Em 2008 foi implementada uma estratégia multimodal para prevenir e controlar o MRSA neste hospital, de cerca de 400 camas, nomeadamente com (1) aplicação universal das precauções básicas (incluindo os cinco momentos para a higiene das mãos); (2) realização de rastreio ativo e medidas de isolamento numa população selecionada e (3) descolonização de doentes em casos específicos, a par de uma monitorização contínua, no âmbito do sistema de vigilância epidemiológica de 'microrganismos problema' em vigor nesta instituição de saúde.

Para concretizar especificamente estes objetivos, implementamos as seguintes ações: (1) publicação do procedimento 'Estratégia Global para Prevenção e Controlo do MRSA' como norma aprovada pelo Conselho de Administração da instituição; (2) revisão das normas 'Precauções Básicas em Controlo de Infeção' e 'Precauções de Isolamento em Controlo de Infeção'; (3) reforço dos pontos de desinfeção alcoólica das mãos, existentes à entrada e no interior de todas as enfermarias e quartos, em todas as camas (exceto na Pediatria), além de outros locais onde há prestação de cuidados de saúde (ex: salas de tratamento, consultórios médicos) ou considerados com um risco semelhante (ex: salas de limpos/ sujos, salas de preparação medicação); (4) realização de sessões de divulgação e esclarecimento aos profissionais de saúde (incluindo chefias de enfermagem, médicas e elos dinamizadores de controlo de infeção dos diversos serviços); (5) implementação da 'Folha alerta de MRSA - Informação aos Profissionais de Saúde' colocada no processo de todos os doentes MRSA positivo; (6) disponibilização do panfleto de informação 'Saiba mais sobre o MRSA' distribuído aos doentes em que foi detetado MRSA e respetivas visitas; (7) implementação de rastreio ativo efetuado por zaragatoa a nível nasal, com deteção do gene mecA por Polymerase Chain Reaction (PCR) em tempo real, com resultado obtido em cerca de duas horas e (8) auditorias aos procedimentos instituídos.

O pilar básico de atuação da estratégia consiste na implementação imediata de medidas de isolamento de contacto e colheita de rastreio ativo perante as seguintes situações: a) doentes transferidos de outros hospitais e lares (com internamento superior a $24 \mathrm{~h}$ na outra instituição) ou cuidados continuados; b) doentes do Serviço de Medicina Intensiva (SMI) e Unidade de Cuidados Intermédios Polivalente (UCIP): na admissão nestas unidades quando provenientes de outros serviços cujo rastreio nasal tenha sido feito há mais de 48 horas, na alta do SMI e UCIP cujo rastreio nasal tenha sido feito há mais de 48 horas e a cada sete dias de internamento nestas unidades; c) nos restantes serviços de internamento: aos contactos diretos (doentes da mesma enfermaria) sempre que detetado um novo caso de MRSA nas culturas pedidas por razões clínicas e d) doentes com antecedentes de colonização e/ou infeção por MRSA (informação registada nas cartas de alta de internamentos anteriores e, no processo do doente, pelo médico e enfermeiro responsáveis). Desde 2012 este rastreio ativo também é efetuado a doentes sujeitos a hemodiálise. Perante um resultado da zaragatoa nasal negativo, as medidas de isolamento de contacto são levantadas (exceto se existir outra razão para as manter, por exemplo: colonização ou infeção por outro 'microrganismo problema'), caso contrário o doente permanece isolado até ter alta.

A descolonização dos doentes é efetuada somente naqueles internados no SMI e UCIP ou, em casos particulares, em que se considere que seja para benefício clínico do doente (por ex: no caso de múltiplas infeções por 
MRSA) e após consultadoria do Serviço de Infeciologia. A descolonização de profissionais de saúde não é aconseIhada, somente no caso de se suspeitar existir colonização persistente associada a transmissão cruzada (neste caso a Comissão de Controlo de Infeção e Serviço de Saúde Ocupacional deverão fazer o acompanhamento do caso). O procedimento definido para descolonização consiste, a nível nasal, lavagem das narinas com soro fisiológico e aplicação de mupirocina a $2 \%$, duas vezes por dia durante cinco dias e, a nível da pele, banho diário com sabão antissético com ação sobre o MRSA durante cinco dias.

Uma vez efetuada a descolonização, deverá monitorizar-se a sua eficácia, com realização de três rastreios de follow-up (o primeiro 48 horas após terminar o tratamento e os restantes com intervalos semanais), até ser considerado de baixo risco de estar colonizado. Se a primeira descolonização falhar poderá repetir-se o procedimento, nunca se efetuando mais que dois cursos de descolonização.

No âmbito do sistema de vigilância epidemiológica da instituição, sempre que é detetado novo caso de MRSA, o Laboratório de Microbiologia alerta a Comissão de Controlo de Infeção e esta procede ao levantamento de dados no processo eletrónico do doente, registando numa base de dados interna. De seguida, é contactado o serviço onde o doente está internado para verificar se as medidas de isolamento estão implementadas e se há critérios para realizar rastreio ativo a outros doentes. No caso do doente ter sido transferido, ou ter tido alta para os cuidados primários, é efetuado um contacto telefónico ou via e-mail com a instituição recetora.

Para monitorizar a eficácia da estratégia implementada recorremos a dois indicadores propostos por Horan e
Gaynes: ${ }^{12}$ a proporção (em que o numerador são as estirpes resistentes à meticilina e o denominador o total de isolamentos de Staphylococcus aureus) e a densidade de incidência (em que o numerador também são as estirpes resistentes à meticilina e o denominador os dias de internamento). A análise estatística dos dados foi feita recorrendo ao programa OpenEpi. ${ }^{13}$ Nos dados laboratoriais foi utilizado o critério de eliminação de duplicados recomendado pelo Clinical and Laboratory Standards Institute. ${ }^{14}$

\section{RESULTADOS}

Em 2007, ano da implementação da estratégia, a proporção de MRSA era de $66 \%$, tendo decrescido para $62 \%$ no ano seguinte, mas aumentado três pontos percentuais em 2009 (Fig. 1). Em 2010 verificámos um decréscimo de $65 \%$ para $56 \%$, para estabilizar nos $57 \%$ nos anos 2011 e 2012. Ao considerar-se o indicador densidade de incidência, detetámos um decréscimo de 1,80 para 1,20 casos por mil dias de internamento de 2007 para 2008. Em 2009 regista-se um ligeiro aumento para 1,30 e, em 2010 e 2011, diminuir para 0,95 casos por mil dias de internamento. Em 2012 ocorreu novo decréscimo para 0,68 casos por mil dias de internamento.

\section{DISCUSSÃO}

Tal como orientações Britânicas ${ }^{15}$ e Norte-Americanas $^{16-18}$ recomendam, aplicámos uma estratégia multimodal, cujo pilar básico assenta na conjugação de realização de rastreios ativos e aplicação de medidas de isolamento em doentes colonizados ou infetados com MRSA. Várias instituições de saúde têm implementado estratégias baseadas nestas recomendações: Yang et al referem que, em

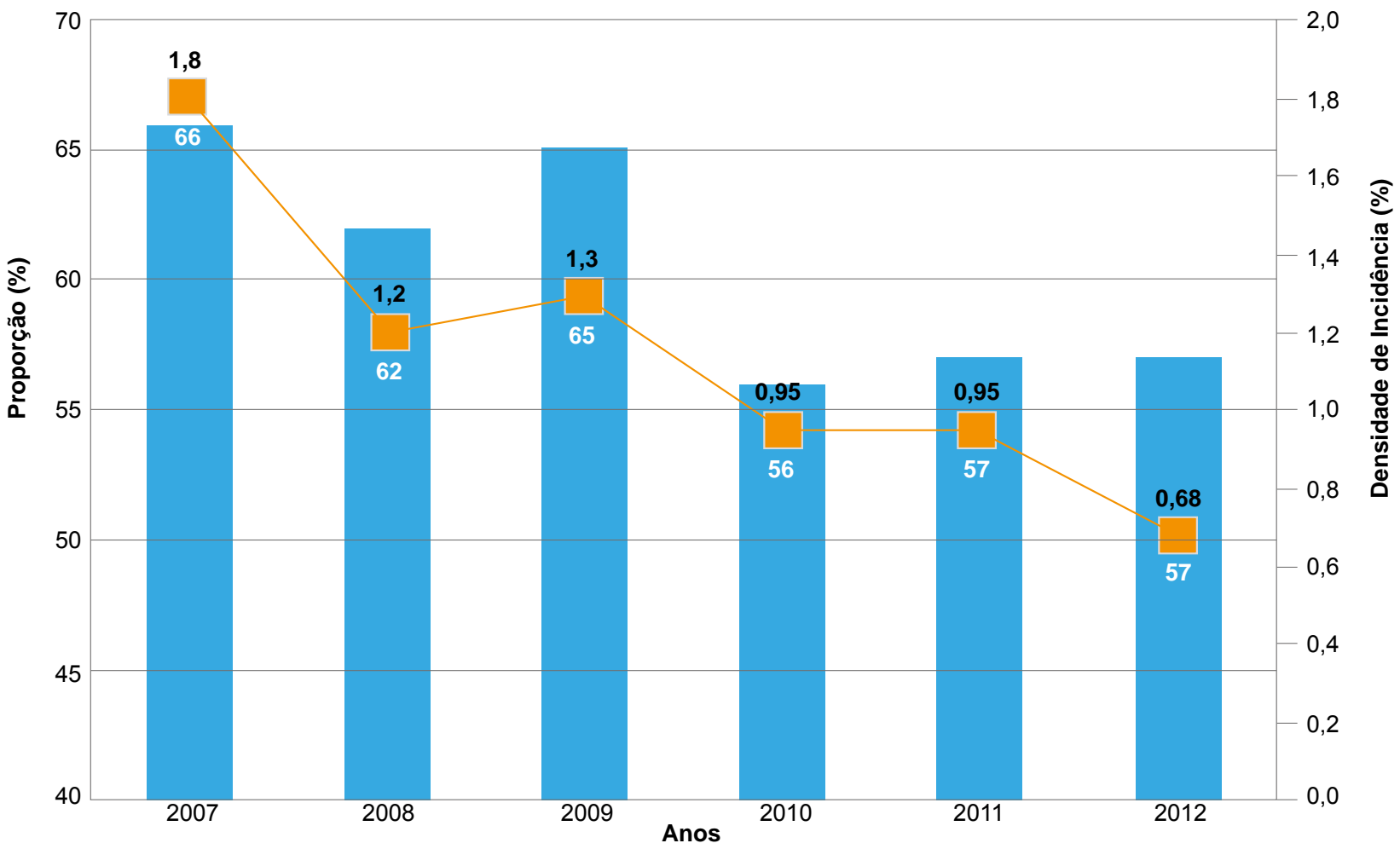

Figura 1 - Evolução da proporção e densidade de incidência de MRSA entre 2007 e 2012, no Hospital Pedro Hispano 
102 hospitais norte-americanos, 44\% tinham um protocolo para realização de rastreios ativos e que, em aproximadamente $25 \%$, existiam um procedimento para descolonização de MRSA. ${ }^{19}$ Num Centro Hospitalar norte-americano aplicou-se uma estratégia faseada: o primeiro designado período base, um segundo em que se realizou rastreio ativo e descolonização aos doentes admitidos nos cuidados intensivos e um último em que tal estratégia foi aplicada universalmente para todas as admissões. Os autores descrevem um decréscimo na densidade de incidência de 0,$89 ; 0,74$ ( $p=0,15$ comparado com o período base) e 0,39 casos ( $p<0,001$ comparado com o período base), respetivamente, por mil dias de internamento, concluindo que o rastreio ativo universal permitiu uma redução substancial do MRSA, durante o internamento e até 30 dias pós-alta. $O$ estudo refere, ainda, que se a identificação dos casos de MRSA fosse somente através de culturas pedidas por razões clínicas (portanto, sem aplicação de rastreio ativo) ter-se-ia somente detetado $17,8 \%$ dos casos. ${ }^{20}$ Por sua vez, num hospital espanhol, os autores conseguiram uma redução implementando rastreio ativo e descolonização numa população selecionada (doentes admitidos de outras unidades hospitalares) de 0,56 para 0,07 casos por mil dias de internamento. ${ }^{21}$ Fraser et al também alcançaram uma redução de 6,38 para 3,32 casos ( $p=0,04$; RR 0,53; IC95\%: $0,28-0,97)$ por mil dias de internamento ao aplicar rastreio ativo e descolonização numa $\mathrm{UCl}$ de 18 camas. ${ }^{22}$ Por outro lado, num estudo britânico envolvendo seis hospitais foram levantadas algumas questões relativas à dificuldade de colocar em prática uma estratégia combinada de rastreio ativo e descolonização universal, nomeadamente: dificuldade em rastreio universal (abrangendo somente $88 \%$ dos casos) ou no processo de descolonização (atingindo $41 \%$ dos casos) devido à mobilidade dos doentes e curta duração dos internamentos, bem como a falta de estrutura física para isolamento dos doentes, deixando dúvidas relativamente ao papel da descolonização na redução do risco no ambiente hospitalar, preferindo frisar a importância das precauções em controlo de infeção. ${ }^{23}$ De facto, não basta implementar rastreios ativos se não existirem condições da estrutura física e boas práticas por parte dos profissionais para levar a cabo as precauções básicas e de isolamento. É importante, ainda, referir que a descolonização nasal com mupirocina por rotina é desaconselhada por vários autores devido ao risco do surgimento de resistências, bem como a sua falta de eficácia a longo prazo. ${ }^{15-17}$ No entanto Coia et al e, mais recentemente, Liu et al salvaguardam que a sua utilização seletiva poderá ser útil em grupos de doentes específicos, ${ }^{15,24}$ como é o caso do protocolo que implementamos em que se definiu descolonizar somente os doentes internados no SMI e UCIP ou em situações muito específicas. Mesmo não recorrendo à descolonização, Martinez-Capolino et al descrevem uma redução da incidência de infeção nosocomial por MRSA, num departamento de cuidados intensivos com 47 camas, recorrendo somente a rastreio ativo (na admissão e semanalmente) e medidas de isolamento dos doentes com resultado positivo durante todo o período de internamento $(0,63$ para 0,31 casos por mil dias de internamento). ${ }^{25}$ Vários estudos têm analisado sob o ponto de vista de eficácia e custo-efetividade a aplicação de rastreios ativos universais (isto é, para todos os doentes) versus em populações selecionadas, não havendo ainda consenso sobre este assunto, devendo as várias unidades hospitalares ponderar tal decisão considerando os dados epidemiológicos locais, as práticas de controlo de infeção e as características da população servida. ${ }^{26}$

$\mathrm{Na}$ estratégia que implementamos optou-se por realizar rastreio ativo numa população selecionada que se considerou de maior risco, designadamente: com historial de MRSA ou internamentos anteriores; proveniente de outras instituições de saúde e lares; admitidos no SMI e UCIP; contactos diretos (doentes da mesma enfermaria) de novos casos de MRSA e, desde 2012, em doentes sujeitos a hemodiálise. Optamos, ainda, por um rastreio rápido por técnica de PCR em tempo real que, apesar de mais dispendioso que as técnicas culturais, permite reduzir o tempo em que o doente está sujeito a medidas de isolamento enquanto aguarda o resultado e, consequentemente, a possível ocorrência de eventos adversos derivados ao doente estar isolado, tal como descrito noutros estudos. ${ }^{27,28}$

Esta estratégia revelou ser eficaz, tendo-se detetado uma redução estatisticamente significativa de 1,80 para 0,68 casos por mil dias de internamento $(p<0,001$; RR 0,38; IC95\%: 0,29-0,49) num período de 5 anos. No entanto, esta diminuição não foi constante, com um aumento de casos em 2009. Tal poderá ser explicado por falhas na aplicação do protocolo instituído, nomeadamente, omissão de colheita de rastreio em doentes com indicação; realização de rastreio sem implementação concomitante das medidas de isolamento de contacto e falha na sinalização dos doentes em isolamento (observadas em auditorias realizadas e, posteriormente, corrigidas). Estas auditorias permitiram, ainda, identificar outros doentes de risco, na transmissão cruzada deste microrganismo, nomeadamente doentes em hemodiálise.

Se considerarmos o indicador 'proporção de MRSA', de acordo com dados da European Antimicrobial Resistance Surveillance Network, Portugal foi o país com maior proporção de MRSA em 2011. ${ }^{4}$ Nesta rede de vigilância participaram 22 hospitais portugueses com 1507 amostras (somente sangue e líquor). Utilizando este critério de inclusão, o nosso hospital revelou, em 2011, uma proporção de MRSA inferior à média nacional (34\% versus 55\%).

No seguimento da monitorização do MRSA através de vigilância epidemiológica consideramos, ainda, imprescindível dar informação de retorno aos profissionais de saúde da evolução das resistências. Para tal, anualmente realizamos uma sessão de divulgação de resultados, organizada conjuntamente com o Laboratório de Patologia Clínica, Comissão de Antimicrobianos e Comissão de Controlo de Infeção. Os dados são, ainda, disponibilizados no website da instituição. 


\section{CONCLUSÕES}

A implementação de uma estratégia multimodal, num hospital com valores endémicos de MRSA, baseada no rastreio ativo de uma população selecionada; na implementação e monitorização de medidas de isolamento em doentes com suspeita ou confirmação de colonização ou infeção por MRSA e descolonização daqueles internados em unidades críticas permitiu, num período de cinco anos, uma redução da proporção e densidade de incidência deste microrganismo multirresistente. Consideramos que a definição desta estratégia como normativa, aprovada pelo Conselho de administração da instituição, foi o que permitiu a sua aplicação transversal a todos os serviços de internamento. Por fim, além de um sistema de vigilância epidemiológica instituído, salvaguardamos a necessidade de monitorizar continuamente a aplicação do procedimento instituído através de auditorias, com informação de retorno aos profissionais de saúde.

\section{AGRADECIMENTOS}

Os autores gostariam de agradecer a todos os profissionais da Unidade Local de Saúde de Matosinhos pelo seu empenho na aplicação quotidiana das boas práticas em controlo de infeção e, mais especificamente, na prossecução da estratégia para controlar o MRSA.

\section{CONFLITOS DE INTERESSE}

Os autores declaram a inexistência de conflitos de interesse relativamente ao presente artigo. Os autores declaram ainda que os resultados expressos neste trabalho foram parcialmente apresentados sob forma de poster nas 7as Jornadas de Actualização em Doenças Infecciosas do Hospital Curry Cabral. Lisboa; Janeiro 2010 (1 Prémio); 22nd European Congress of Clinical Microbiology and Infectious Diseases. Londres; Abril 2012 e 2nd International Conference on Prevention \& Infection Control. Genebra; Junho 2013.

\section{FONTES DE FINANCIAMENTO}

$O$ trabalho foi realizado sem o suporte de qualquer bolsa ou outro tipo de apoio financeiro.

Pennsylvania: Clinical and Laboratory Standards Institute; 2005.

15. Coia JE, Duckworth GJ, Edwards DI, Farrington M, Fry C, Humphreys $\mathrm{H}$, et al. Guidelines for the control and prevention of meticillin-resistant Staphylococcus aureus (MRSA) in healthcare facilities. J Hosp Infect. 2006;63:S1-44.

16. APIC. Guide to the elimination of methicillin-resistant staphylococcus aureus (MRSA) Transmission in hospital settings. Washington: Association for Professionals in Infection Control and Hospital Epidemiology; 2007. [Consultado em 2013 Maio 07] Disponível em: http://www.apic. org.

17. Siegel JD, Rhinehart E, Jackson M, Chiarello L, HICPAC. Management of multidrug-resistant organisms in healthcare settings, 2006. Am J Infect Control. 2007;35:S165-93.

18. Calfee DP, Salgado CD, Classen D, Arias KM, Podgorny K, Anderson DJ, et al. Strategies to prevent transmission of methicillin-resistant Staphylococcus aureus in acute care hospitals. Infect Control Hosp Epidemiol. 2008;29:S62-80.

19. Yang Y, McBride MV, Rodvold KA, Tverdek F, Trese AM, Hennenfent $\mathrm{J}$, et al. Hospital policies and practices on prevention and treatment of infections caused by methicillin-resistant Staphylococcus aureus. Am J Health Syst Pharm. 2010;67:1017-24.

20. Robicsek A, Beaumont JL, Paule SM, Hacek DM, Thomson RB Jr, Kaul $\mathrm{KL}$, et al. Universal surveillance for methicillin-resistant Staphylococcus aureus in 3 affiliated hospitals. Ann Intern Med. 2008;148:409-18.

21. Rodríguez-Baño J, García L, Ramírez E, Lupión C, Muniain MA, Velasco $\mathrm{C}$, et al. Long-term control of endemic hospital-wide methicillinresistant Staphylococcus aureus (MRSA): the impact of targeted active surveillance for MRSA in patients and healthcare workers. Infect Control Hosp Epidemiol. 2010;31:786-95.

22. Fraser TG, Fatica C, Scarpelli M, Arroliga AC, Guzman J, Shrestha NK, et al. Decrease in Staphylococcus aureus colonization and hospitalacquired infection in a medical intensive care unit after institution of an active surveillance and decolonization program. Infect Control Hosp Epidemiol. 2010;31:779-83.

23. Reilly JS, Stewart S, Christie P, Allardice G, Smith A, Masterton R, et al. Universal screening for meticillin-resistant Staphylococcus aureus: interim results from the NHS Scotland pathfinder project. J Hosp Infect. 2010;74:35-41.

24. Liu C, Bayer A, Cosgrove SE, Daum RS, Fridkin SK, Gorwitz RJ, et al. Clinical practice guidelines by the infectious diseases society of america for the treatment of methicillin-resistant Staphylococcus aureus infections in adults and children. Clin Infect Dis. 2011;52:e18-55.

25. Martinez-Capolino C, Reyes K, Johnson L, Sullivan J, Samuel L, Di- 
giovine B, et al. Impact of active surveillance on meticillin-resistant Staphylococcus aureus transmission and hospital resource utilisation. J Hosp Infect. 2010;74:232-7.

26. Harbarth S, Hawkey PM, Tenover F, Stefani S, Pantosti A, Struelens MJ. Update on screening and clinical diagnosis of meticillin-resistant Staphylococcus aureus (MRSA). Int J Antimicrob Agents. 2011;37:110-7.
27. Stelfox HT, Bates DW, Redelmeier DA. Safety of patients isolated for infection control. JAMA. 2003;290:1899-905.

28. Tarzi S, Kennedy P, Stone S, Evans M. Methicillin-resistant Staphylococcus aureus: psychological impact of hospitalization and isolation in an older adult population. J Hosp Infect. 2001;49:250-4. 


\section{Estratégia para Controlar o Staphylococcus Aureus Resistente à Meticilina: A Experiência de Cinco Anos de um Hospital Acta Med Port 2014:27:67-72}

Publicado pela Acta Médica Portuguesa, a Revista Científica da Ordem dos Médicos

Av. Almirante Gago Coutinho, 151

1749-084 Lisboa, Portugal.

Tel: +351218428215

E-mail: submissao@actamedicaportuguesa.com

www.actamedicaportuguesa.com

ISSN:0870-399X | e-ISSN: 1646-0758

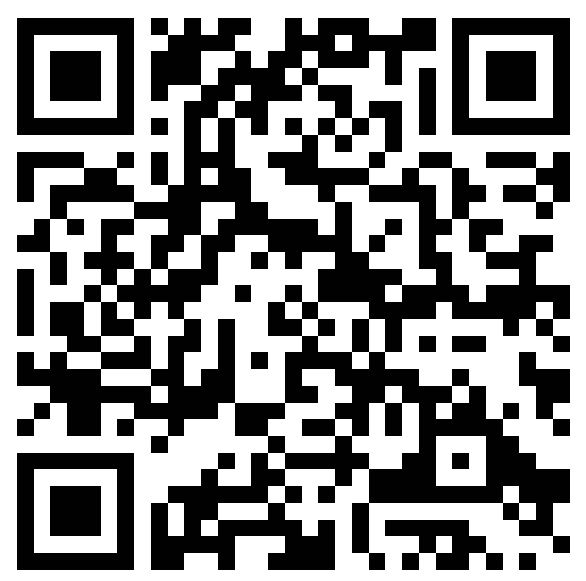

